\title{
ESTUDOS BIBLIOMÉTRICOS (?) EM ADMINISTRAÇÃO: DISCUTINDO A TRANSPOSIÇÃO DE FINALIDADE
}

\author{
BIBLIOMETRIC STUDIES (?) IN BUSINESS ADMINISTRATION: \\ DISCUSSING THE TRANSPOSITION OF PURPOS
}

Recebido em: 2/12/2012 Aprovado em: 21/03/2013 Avaliado pelo sistema double blind review Editora Científica: Manolita Correia Lima

\section{MARIA LUISA MENDES TEIXEIRA malluluisa@gmail.com UNIVERSIDADE PRESBITERIANA MACKENZIE}

\section{HELGA MIDORI IWAMOTO}

ANA LÚCIA MEDEIROS

UNIVERSIDADE PRESBITERIANA MACKENZIE

\begin{abstract}
RESUMO
Nos últimos anos tem-se verificado uma crescente produção de estudos bibliométricos em Administração sobre os mais diferentes assuntos. Qual a finalidade desses artigos? Que técnicas empregam? Essas e outras questões nos levaram a conduzir este estudo e reflexão. Este artigo teve como objetivo analisar e discutir a produção de estudos bibliométricos em Administração no Brasil, propondo uma reflexão sobre o emprego da bibliometria e sugerindo alternativas para o emprego de técnicas de forma que atendam a finalidade de subsidiar a pesquisa em Administração, vislumbrando possíveis avanços a serem feitos sobre um campo específico de estudo. O estudo consistiu em um levantamento de natureza biblométrica de artigos publicados em periódicos científicos brasileiros e ENANPAD. Os resultados mostraram que os artigos apresentam categorias que não são contempladas pela bibliometria, mostrando que as técnicas tradicionais da bibliometria não atendem completamente às necessidades dos pesquisadores que os realizam. Propõe-se, assim, a adequação do método, fazendo uma transposição de finalidade, abarcando análises e reflexões sobre o conhecimento dominante que abrigam o não hegemônico.
\end{abstract}

Palavras-chaves: bibliometria; Administração; reflexão.

\section{ABSTRACT}

In recent years there has been an increasing production of bibliometric studies in Business Administration on a variety of different subjects. What is the purpose of these articles? Which techniques are employed? These and other questions led us to conduct this study and reflection. This paper aims to analyze and discuss the production of bibliometric Business Administration studies, in Brazil, proposing a reflection on the use of bibliometrics, and suggesting alternatives to employing techniques in order to meet the purpose of assisting Business Administration research. Possible advances in a specific field of study are envisioned. The study consisted of a bibliometric research of papers published in Brazilian scientific journals and ENANPAD. The results showed that the papers include categories not covered by bibliometrics, thereby demonstrating that traditional bibliometric techniques fail to fully meet the needs of the researchers who use them. The paper thus proposes the adaptation of the method by making a transposition of purpose, contemplating analyzes and reflections on the dominant knowledge to cover non-hegemonic issues. Keywords: bibliometrics; Business Administration; reflection. 


\section{INTRODUÇÃO}

Em uma rápida passada de olhos pela produção científica em Administração veiculada em revistas e eventos científicos brasileiros, os mais importantes, nos últimos anos, chamou-nos a atenção a pequena, porém crescente, produção de estudos bibliométricos sobre os mais diferentes assuntos. Qual a finalidade desses artigos? Que técnicas empregam? Essas e outras questões nos levaram a conduzir este estudo e reflexão.

A bibliometria, termo cunhado por Pritchard (1969), consiste em um conjunto de leis associadas à Ciência da Informação que se desenvolveu baseada na Teoria da Informação mas que, no entanto, possui teorias próprias (BRAGA, 1973). A Ciência da Informação tem como objeto de estudo o fenômeno da comunicação e "[...] estuda o comportamento, as propriedades, e os efeitos da informação em todas as suas facetas, bem como processos de comunicação que afetam e são afetados pelo homem", processos esses "efetuados através de sistemas" (BRAGA, 1973, p. I0). Envolve, assim, a bibliometria, cienciometria, informetria e webmetria, que, segundo Araújo (2002), consistem em subdisciplinas ou, ainda, subcampos da Ciência da Informação, para aludir ao entendimento de Vanti (2002).

Segundo Vanti (2002), a principal diferença entre os subcampos está no objeto de estudo, o que gera variáveis observáveis e métodos diferenciados, isso de acordo com o objetivo em questão. A bibliometria volta-se para a produção existente entre livros, documentos e periódicos, enquanto a cienciometria procura descrever os avanços em campos científicos e tecnológicos via análise de patentes e teses. Já no que toca à informetria, analisa a geração de conhecimento científico, ou não em canais de comunicação informal, como os meios tradicionais de comunicação de massa (TV, revistas, etc.) e a internet, ao passo que a webometria se ocupa das estatísticas de acesso a endereços de internet e das obtidas pelas ferramentas de busca na internet.

De acordo com Macias-Chapula (1998), a bibliometria permite, mediante a geração de índices, avaliar a produção científica de um país, das instituições e dos cientistas. Possibilita, também, macroanálises, como a da produção 
científica de um país em relação ao mundo, bem como microanálises, no caso da relação entre a produção acadêmica de um pesquisador e a comunidade científica em que se insere e, quanto ao objetivo, focaliza-o na alocação de recursos. A cienciometria, por sua vez, objetiva identificar domínios de interesse, verificando onde os assuntos estão concentrados, buscando compreender como os cientistas se comunicam. Diferentemente, a informetria procurar melhorar a eficiência na recuperação do conhecimento.

Mais recentemente, a bibliometria tem se diversificado e, sob uma nova perspectiva, agora não mais concentrando seu foco na mensuração, mas na compreensão contextualizada da produção científica e de seus produtores, para quem as técnicas bibliométricas desempenham um papel de parceria em associação com abordagens teóricas (ARAÚJO, 2002).

Como podemos perce ber, a bibliometria e campos afins têm como objetivo a mensuração do conhecimento ou a compreensão sobre sua produção. Não seria, portanto, em princípio, essa a finalidade do uso da bibliometria ao fazermos estudos bibliométricos em Administração, uma vez que tal é precípua à Ciência da Informação. Qual a finalidade, então, do emprego de estudos bibliométricos em Administração?

Mattos (2004, p.2), ao fazer uma análise crítica do artigo de Tonelli, Caldas, Lacombi e Tinoco (2003) comenta: "minha dificuldade fundamental é que a estrutura e a metodologia ali adotadas não permitem justificar por que se monta o entendimento de determinada maneira, nem porque se organiza o mapa com determinadas configurações [...]”. Talvez esteja aqui o cerne da questão: estaríamos importando técnicas da ciência da informação para uma finalidade estranha à qual foram criadas?

Este artigo tem como objetivo analisar e discutir a produção de estudos bibliométricos em Administração no Brasil, propondo uma reflexão sobre o emprego da bibliometria, de maneira a sugerir alternativas para o uso das técnicas segundo formas que atendam à finalidade de subsidiar a pesquisa sobre um determinado tema. Objetivamos, ainda, nos debruçar sobre o status quo e vislumbrar, a partir daí, possíveis avanços a serem feitos sobre um campo específico de estudo em Administração. 


\section{BIBLIOMETRIA: FINALIDADE, LEIS E CATEGORIAS BIBLIOMÉTRICAS}

A bibliometria nasceu nos anos sessenta do século $\mathrm{xx}$ e foi assim nomeada por Pritchard (1969) e, por ter caráter quantitativista, orientou a formulação de leis matemáticas, cujo objetivo é o de mensurar a produção cientifica. Alguns autores apresentam definições para o termo e um em particular, Braga (1973, p.Io), define-a como um conjunto de leis destinadas ao "tratamento quantitativo das propriedades e do comportamento da informação registrada”. Dentre essas leis, podemos destacar: a de Lotka, a de Zipf e a de Bradford. A lei de Lotka (1926) postula que x artigos são produzidos por $\mathrm{k} / \mathrm{x}^{\alpha}$ pesquisadores, tendo em vista que a constante $\mathrm{k}$ valeria aproximadamente $6 / \pi^{2}$. Na lei de Price (1963), um aperfeiçoamento da Lei de Lotka, a conclusão é de que menos de i/ıo dos autores produzem aproximadamente $\mathrm{I} / 3$ do conhecimento científico de uma área, segundo atesta Araújo (2002).

A lei de Bradford (1934) relaciona o número dos artigos de determinada área à distribuição deles nos periódicos e, de outra maneira, a lei de Zipf(1949) coloca-se como um modelo, relacionando palavras-chave e a classificação do documento em determinada área. No texto de James Joyce, analisado por Zipf, a palavra mais utilizada aparecia 2.653 vezes, enquanto que a centésima 256 e a duocentésima 133 vezes. Segundo Araújo (2002), a frequência total de cada palavra multiplicado pela a ordem de grandeza em que aparecem no texto (p. ex., primeira que mais aparece, segunda que mais aparece, etc.) resultam numa constante. Nesse modelo, a palavra mais utilizada indicaria o assunto do texto, a exceção dos advérbios, conjunções, etc. Podem ser utilizadas de forma auxiliar as técnicas de análise de discurso (Bardin, 1979), para inferência do significado desejado pelos autores em cada contexto em que as palavras-chaves (mais frequentes) aparecem.

De acordo com Araújo (2002), a bibliometria atualmente tem seguido dois caminhos distintos: um, dando continuidade ao enfoque original, persegue a trilha do aperfeiçoamento das leis de mensuração e, outro, que questiona a validade dos estudos exclusivamente quantitativos. Autores desta linha de entendimento questionam inclusive a bibliometria enquanto 
disciplina de conhecimento, propondo que seja entendida apenas como técnica, e de apoio, a ser empregada na realização de diferentes estudos, o que tem fomentado a sua utilização nas Ciências Sociais. (ARAÚJO, 2002). Como exemplo, Araújo (2002) cita trabalhos de Alvarenga (1998) sobre a historicidade da produção científica com base na arqueologia do saber de Foucault, entre outros. Segundo o autor, "são trabalhos que se utilizam de dados bibliométricos, mas que realizam uma leitura desses dados à luz de elementos do contexto sociohistórico em que a atividade científica é produzida" (ARAÚJO, 2002, p. 25).

Com uma finalidade ou outra, quer mensuração, quer compreensão da produção científica sob a ótica de um contexto específico, ou abordagem teórica, a bibliometria se vale da análise da produção científica mediante categorias. Segundo autores da área (p. ex. Wormell, 1998; Vanti, 2002), são cinco os principais tipos de metodologia utilizados pela bibliometria: análise de citações, análise de cocitação, agrupamento bibliográfico, coword analysis, e "webometria".

Para Araújo (2002), a análise de citações, com origem no século XVII, é a área mais importante da bibliometria e engloba quesitos como autores mais citados, autores mais produtivos, elite de pesquisa, frente de pesquisa, fator de impacto dos autores, procedência geográfica e institucional dos autores e da literatura mais influentes de uma área, tipo de documento mais utilizado, idade média da literatura utilizada, obsolescência da literatura e periódicos mais citados (core de periódicos). A análise da produtividade dos autores leva em conta quais autores mais publicam, quais os mais citados e a mudança do padrão de citação dos autores ao longo dos anos.

Algumas dessas categorias implicam o emprego de leis como "elite de pesquisa", que é mensurada com base na raiz quadrada do total de autores da área, do que resulta a estimativa do tamanho da elite de determinada população de autores (PRICE, 1963). A frente de pesquisa, em contrapartida, seria constituída pelas publicações (artigos, capítulos, livros, etc.) mais citadas em uma determinada área (BRAGA, 1973). Segundo Garfield (2005), criador do Science Citation Index (SCI), em 1963, o fator de impacto de um periódico em um determinado período é encontrado dividindo-se o total de 
artigos de um jornal pela quantidade de "artigos substantivos" do mesmo jornal dentro do período dos últimos dois anos. Esse fator tem influenciado as políticas nacionais de avaliação dos periódicos, no sentido de identificar as instituições e os autores com maior número de citações para financiamento de projetos de pesquisa.

Alguns estudos foram desenvolvidos para analisar as causas do impacto, e, dentre esses, podemos destacar Podsakoff (2008), que identificou ser a variável tamanho da universidade, algo que influencia em todas as três variáveis mediadoras: número de doutores formados por ano, investimentos em pesquisa partindo da universidade e recursos para pesquisa injetados na universidade. Essas três variáveis, por sua vez, influenciam no número de publicações e, consequentemente, no número de citações.

A relação entre as categorias citações e reputação da universidade pode estar relacionada ao fato de que instituições de ensino superior bem avaliadas têm em seus quadros pesquisadores produtivos em decorrência de forte cultura de pesquisa da própria instituição, da política institucional bem definida para a pesquisa e para a pós-graduação, da qualidade dos programas de iniciação científica, de pós-graduação, do ensino superior e da qualificação do corpo docente. Acredita-se que uma universidade bem avaliada e com boa reputação pode tornar-se referência e atrair bons pesquisadores para compor o quadro docente.

Elite de pesquisa e fator de impacto são exemplos de análises que têm como foco a análise da produção e da produtividade dos pesquisadores sob um prisma de mensuração, que pode ter como um dos objetivos o direcionamento do investimento em pesquisa, considerando-se que essa pode ser uma das utilidades da bibliometria, como menciona MaciasChapula (1998). Outras categorias implicam apenas em contagem como é o caso da procedência geográfica e institucional e do levantamento da literatura mais influente de uma área, idade média da literatura utilizada e obsolescência da literatura. Essas categorias e outras do mesmo tipo, que implicam apenas em contagem, podem se prestar a uma utilidade para a qual não foram criadas e para a qual não são destinadas, com base na perspectiva da Ciência da Informação. 
Estudos realizados por Bertero, Caldas e Wood Jr (1999) analisaram a produção científica no campo das Ciências Administrativas no Brasil e mostraram que houve um significativo crescimento em número de artigos publicados. No entanto, isso não se traduziu em melhoria na qualidade da pesquisa nessa área do conhecimento. Ao analisar a pesquisa científica, os autores assinalaram que os estudos em tal campo do conhecimento apresentavam falhas epistemológicas, metodologias inadequadas, reflexões pouco originais e baixa aplicação prática. (BERTERO; CALDAS; WOOD JR. 1999).

Sugerem, ainda, que esses fatores estão associados ao crescimento acelerado da pós-graduação, à adoção de literatura estrangeira, que torna a produção científica nacional pouco original, além de situada no paradigma funcionalista. Por último, apontam a necessidade de se melhorar a qualidade da pesquisa científica em administração no país e recomendam que sejam empregados critérios mais rigorosos no processo de avaliação de artigos. Dado o lapso de tempo em que essa pesquisa foi realizada, acredita-se que se faz necessária a realização de um novo estudo para avaliar esse mesmo fenômeno nos últimos anos. 


\section{PROCEDIMENTOS METODOLÓGICOS}

Foi escolhida como unidade de análise a produção científica sobre artigos bibliométricos da área de administração de empresas publicados nos principais periódicos nacionais nacionais, que foram selecionados segundo classificação no qualis, sistema definido pela CAPES - Coordenação de Aperfeiçoamento de Pessoal de Nível Superior. Foram filtrados os periódicos que adotam como língua principal a Portuguesa, quer brasileiros ou não, e os brasileiros que assumem, para publicação, a Língua Inglesa, todos incluídos no qualis e classificados nos estratos Bi e A2. Quanto ao período de acesso, esse circunscreveu-se ao mês de outubro de 2012. Em adição, foram consultados os anais de eventos organizados pela ANPAD - Associação Nacional de Pós-Graduação em Administração - na área de Administração.

O critério de seleção dos periódicos, dentre os muitos classificados na área, foi a figuração das seguintes palavras em seus títulos: administração, gestão, organização, organizações, organizacional, organizacionais, administration, administrative, management, business e organization. Essa seleção foi realizada para que fosse acessada a produção no core da área de administração.

As revistas contempladas e classficadas no qualis A2 foram as seguintes: BAR - Brazilian Administration Review; BвR - Brazilian Business Review, (edição em português, online); BвR - Brazilian Business Review (English Edition, online); Gestão \& Produção (UfSCAR - Impressa); Organizações \& Sociedade (Impressa); Organizações \& Sociedade (online); RAC Eletrônica; RAC - Revista de Administração Contemporânea (Impresso); RAC - Revista de Administração Contemporânea (online); RAE (Impressa); RAE Eletrônica (online); Revista de Administração Pública (Impressa) .

No que se refere às selecionadas e compareceram no estrato Bı foram as que seguem: Cadernos EBAPE.BR (FGv); Produção (Impressa); RAI - Revista de Administração e Inovação; RAM - Revista de Administração Mackenzie (Impressa); RAM - Revista de Administração Mackenzie (online); RAusP-e (São Paulo); REAd - Revista Eletrônica de Administração; Revista Brasileira de Gestão de Negócios (online); Revista Brasileira de Gestão de Negócios (Impressa); Revista Brasileira de Gestão e Desenvolvimento Regional; 
Revista de Administração (FEA-USP); Revista de Administração (online); Revista de Ciências da Administração (CAD/UFSC); Revista de Contabilidade e Organizações; Revista de Gestão da Tecnologia e Sistemas de Informação (online); Revista Portuguesa e Brasileira de Gestão (Lisboa); Revista Portuguesa e Brasileira de Gestão.

Em seguida, foram acessados os sites de cada periódico no portal Scielo e realizadas as buscas somente de artigos e eventos que apresentam no título uma ou mais das seguintes palavras: "bibliométrico", "bibliométrica", "bibliométricos", "bibliométricas" e "bibliometria". As escolhas se justificam pelo fato de que se constatou a existência de uma pesquisa preliminar com artigos bibliométicos em Administração em cujos títulos aparecem expressões tais : estudo bibliométrico, análise bibliométrica e o termo bibliometria. Percebeu-se, assim, que tanto revistas, como Gestão da Produção, Produção, RAC, RAC eletrônica, RAE, RAE eletrônica e rEAd, quanto eventos, como enanpad, Encontro de Marketing da AnPad, Simpósio de Gestão da Inovação Tecnológica e ENEO - Encontro Nacional de Estudos Organizacionais, publicaram artigos em que seus títulos continham palavras relacionadas a estudos bibliométricos.

A próxima etapa consistiu na análise de citações dos artigos pesquisados, o que se deu por meio do Microsoft Excel 20Io, resultando na seleção dos 36 artigos que seguem listados: Andrade, Joaquim e Gosling (20I2); Botelho et al. (20II); Caldas, Tinoco e Chu (2003); Caldas e Tinoco (2004); Calvosa (2012); Camargos, Silva e Dias (2009); Cantalice et al. (2010); Chan, Milani Filho e Martins (2007); Cintra, Munck e Vieira (2012); Delfino, Silva e Rohde (2010); Favoreto, Vieira e Shimada (2012); Judice e Pereira (2008); Lacerda, Ensslin e Ensslin (2012); Macedo, Casa Nova e Almeida (2007); Machado-da-Silva et al. (2008); Maldonado, Santos e Santos (2010); Marques, Petri e Schultz (2012); Martins et al. (2007); Mattos (2004); Moretti e Campanario (2008); Moretti e Campanario (2009); Moretti e Figueiredo (2007); Nogami e Pacagnan (20II); Pereira, Carvalho e Rotondaro (20I2); Pereira et al. (20II); Rasera e Cherobim (2010); Rossi, Bortoli e Castilhos (2012); Santos et al. (2012); Schmitt et al. (2012); Sehnem et al. (20I2); Sola e Bonacim (20II); Souza et al. (20Ir); Splitter, Rosa e Borba (20I2); Walter, Bach e Barbosa (2012); Walter e Silva (2008) e Zanini, Pinto e Filippim (2012). 


\section{RESULTADOS}

Os resultados estão apresentados em dois tópicos. Inicialmente foram apresentados os resultados relativos aos autores que mais têm influenciado os estudos bibliométricos em Administração no Brasil e em seguida, as categorias mais utilizadas.

Quem mais tem Influenciado os Estudos Bibliométricos em Administração no Brasil? Neste trabalho são apresentados os resultados de uma análise que tomou por base quais autores são mais citados e por quais artigos. Dos 36 artigos analisados foi contabilizado um total de I.34I referências relativas a I.I63 artigos. A Figura I, apresenta os artigos referenciados mais de três vezes dentre os artigos analisados. 
Figura I Autores mais citados pelos 37 estudos analisados neste artigo

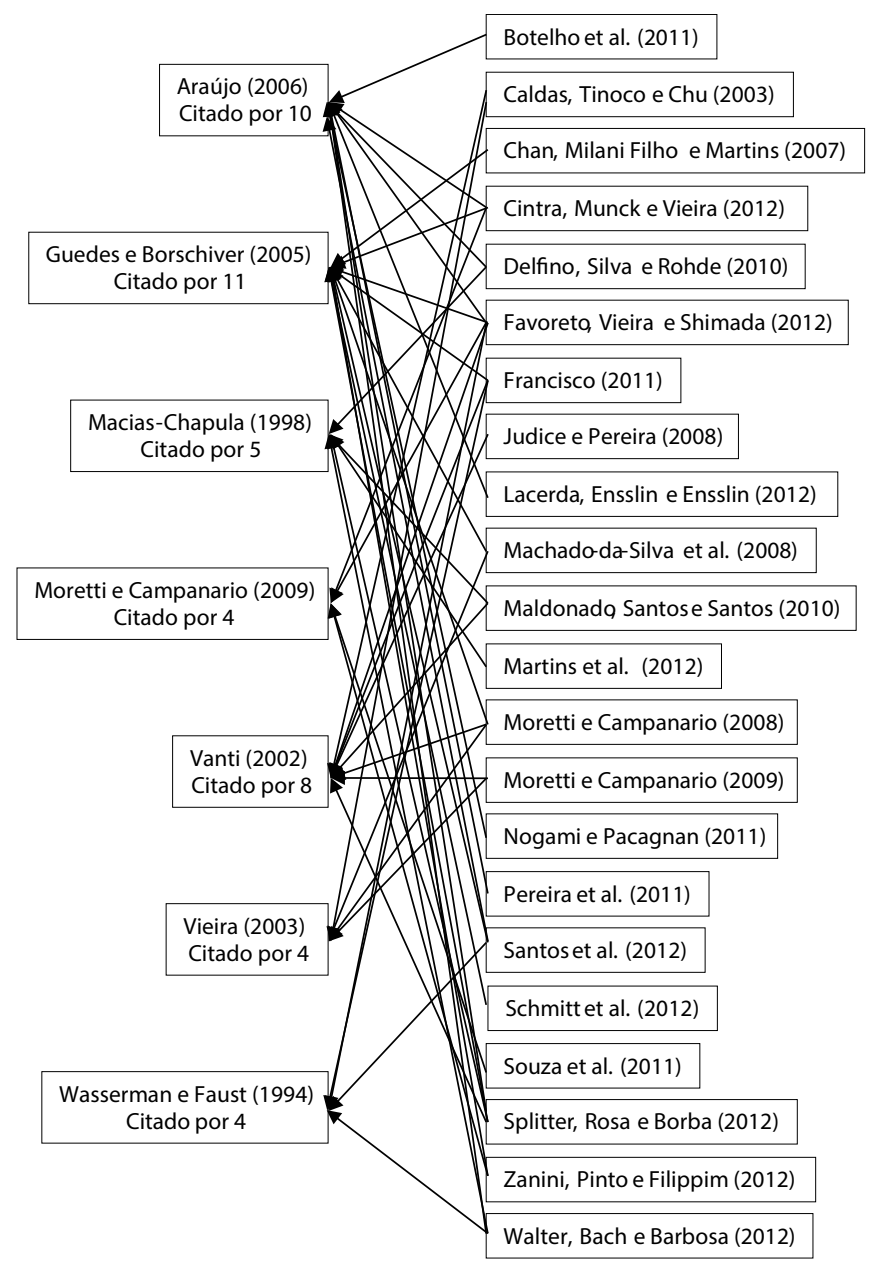

Notou-se que há diferentes razões para que os artigos da coluna da esquerda sejam os mais citados pelos 36 artigos analisados. Por exemplo, Moretti e Campanário (2009) e Vieira (2003) foram considerados artigos bibliométricos de referência em suas respectivas áreas - Responsabilidade Social e Marketing.

Por outro lado, os outros autores pertencem ao campo da Ciência da Informação, sendo citados como referências seminais para trabalhos 
bibliométricos. Vanti (2002), por exemplo, foi a mais citada, tanto pela definição do conceito de bibliometria quanto pela distinção entre bibliometria e conceitos afins como Informetria, Cientometria e Webometria. De forma complementar, Guedes e Borschiver (2005) explicam as razões para o uso das técnicas bibliométricas nas áreas de gestão do conhecimento (cientometria), da informação e da comunicação (informetria). Por seu turno, MaciasChapula (1998) realiza um comparativo entre a perspectiva nacional e a internacional para a informetria e a cienciometria. Araújo (2002), por sua vez, provê um panorama histórico da bibliometria dentro do campo da Ciência da Informação e, por último, abordando as redes de citações entre autores, Wasserman e Faust (1994) descrevem a metodologia e as aplicações da Análise de Redes Sociais.

Neste artigo foram utilizadas inicialmente categorias prescritas por Araújo (2002) para a análise de citações, que são: ano, periódico/evento, estado e instituição(ões) de origem do(s) autor(s). e A categoria ano é utilizada para mapear a produção científica num dado período e, em conjunto com outras, como estado e instituição de origem, pode revelar tendências de crescimento ou decrescimento de publicações por linha de pesquisa e por origem geográfica. A frequência absoluta de artigos bibliométricos por ano de publicação é descrita no Gráfico I. 
Gráfico I Número de artigos bibliométricos por data de publicação

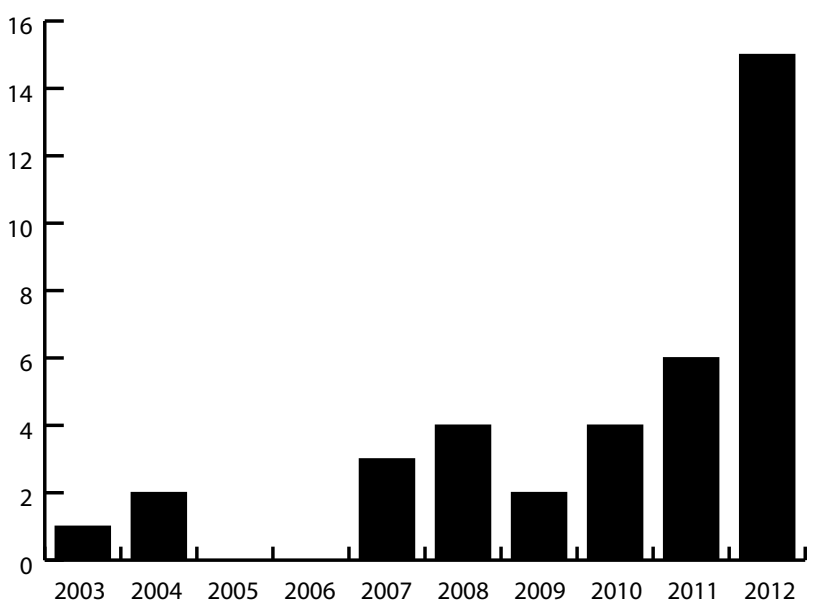

Pode-se perceber que apenas em 2012 foram publicados $40,6 \%$ de todos os artigos bibliométricos encontrados em periódicos e eventos da área de administração. Esse dado denota uma tendência de aumento de interesse nesse tipo de estudo. Essa tendência será analisada em conjunto com as instituições e origem dos autores, assim como dos periódicos e dos eventos que publicaram tais artigos.

No que tange aos veículos utilizados na difusão dos artigos, verificouse que a grande maioria das publicações ocorreu no EnANPAD, que foi responsável pela publicação de 23 artigos dos 36 analisados, conforme mostra o Gráfico 2. O crescimento do número de bibliométricos no enanPaD, desde 2003, foi algo notável, merecendo, entretanto, destaque para o incremento a partir de 20II, dado que, de 2003 a 2010 o volume máximo desse tipo de publicação era de três ao ano, cenário que se modifica com cinco artigos em 201 I e oito em 2012.

Outro fato interessante foi a ampliação das publicações de bibliométricos para outros eventos organizados pela ANPAD em 2012, o que se reflete nestes números: o Encontro de Marketing com dois artigos e o EnEo com um . Essa expansão, porém, ao que parece, não ficou restrita aos da ANPAD, estendo-se a periódicos de Gestão da Produção e para a revista ReAd, predominantemente no ano de 2012. 
No extremo oposto, a RAE, cuja última publicação de bibliométrico havia sido em 2004, quando veiculou dois artigos, voltou a publicá-los depois de sete anos, em 20II, veiculando um estudo congênere.

A rac e o Simpósio de Gestão da Inovação Tecnológica, entre os dois extremos, vêm publicando bibliométricos desde 2008. Outra constatação é que, no geral, não houve publicações duplicadas, a não ser no caso de Moretti e Campanário (2008), publicado originalmente no ENANPAD e, posteriormente, na RAC em 2009.

Gráfico 2 Número de bibliométricos por periódico ou evento

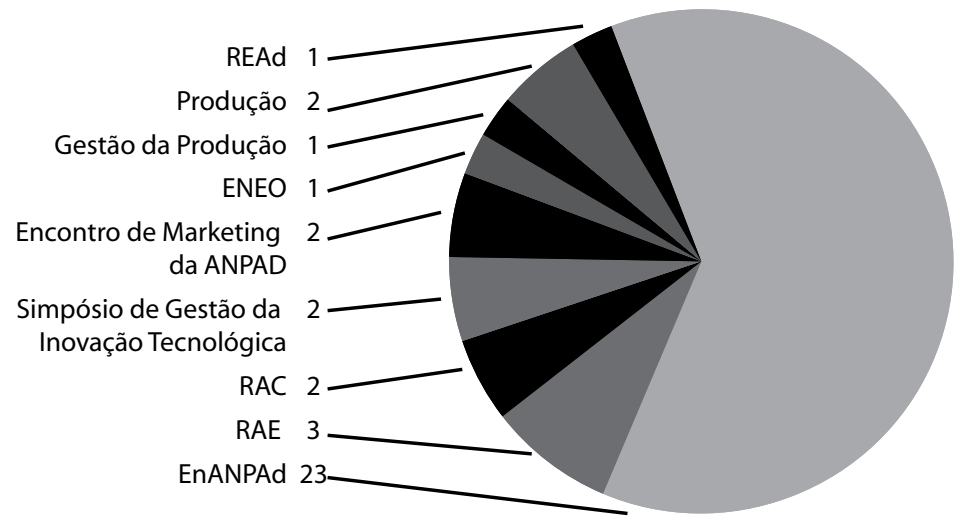

Pode-se perceber no Gráfico 2, que houve uma centralização das publicações em torno do enanpad. Serão identificadas na Tabela I, os estados de origem dos autores, para fins de comparação entre os locais de publicação e os de origem dos autores. Essa categoria reflete a dispersão e a concentração da produção científica, isto é, por meio dela é possível verificar se a produção do conhecimento se encontra concentrada geograficamente. 
Tabela I Local de origem dos autores

\begin{tabular}{|l|l|}
\hline Local & Número de autores \\
\hline Santa Catarina & 38 \\
\hline São Paulo & 27 \\
\hline Paraná & 15 \\
\hline Minas Gerais & 10 \\
\hline Rio Grande do Sul & 4 \\
\hline Ceará & 4 \\
\hline Paraíba & 3 \\
\hline Rio de Janeiro & 3 \\
\hline Pernambuco & 2 \\
\hline Piauí & 2 \\
\hline Tocantins & 2 \\
\hline La Paz - Bolívia & 1 \\
\hline Leiria - Portugal & 1 \\
\hline Mato Grosso & 1 \\
\hline Total & 113 \\
\hline
\end{tabular}

Com base na Tabela I, pode-se constatar que o maior contingente de publicações foi desenvolvido por autores de Santa Catarina, São Paulo, Paraná e Minas Gerais. Os dados mostram que a pesquisa se concentrou nas Regiões Sul e Sudeste do Brasil, majoritariamente nos Estados de Santa Catarina e São Paulo. É digno de nota que o artigo cuja origem remonta ao Estado de Pernambuco não é um bibliométrico no sentido stricto, no entanto o foi assim considerado no estudo por ter o termo bibliométrico em seu título.

O texto em questão foi escrito por Matos (2004), que faz críticas às técnicas bibliométricas utilizadas no mapeamento da produção científica em Recursos Humanos no Brasil, especificamente ao trabalho de Caldas e Tinoco (2004). Já a categoria instituições de origem associada à de origem da literatura mostra o front de elite da pesquisa por região (Tabela 2). 
Tabela 2 Número de autores por instituição

\begin{tabular}{|c|c|c|}
\hline Instituiçōes & Local & $\begin{array}{l}\text { Número de } \\
\text { autores }\end{array}$ \\
\hline Universidade Federal de Santa Catarina & SC & 13 \\
\hline Universidade de São Paulo & SP & 10 \\
\hline Fundação Getúlio Vargas & SP & 7 \\
\hline Fundação Universidade Regional de Blumenau & SC & 7 \\
\hline Associação Educacional Nove de Julho (UNINOVE) & SP & 6 \\
\hline Universidade do Vale do Itajaí & SC & 6 \\
\hline Universidade Estadual de Londrina & PR & 5 \\
\hline Faculdade Novos Horizontes & MG & 4 \\
\hline Universidade Federal do Ceará & CE & 4 \\
\hline Pontifícia Universidade Católica & PR & 3 \\
\hline Universidade do Oeste de Santa Catarina & SC & 3 \\
\hline Universidade Federal de Minas Gerais & MG & 3 \\
\hline Universidade Federal do Paraná & PR & 3 \\
\hline Universidade Federal do Rio Grande do Sul & RS & 3 \\
\hline Sociedade de Ensino Superior Piauiense & $\mathrm{PI}$ & 2 \\
\hline Sociedade Educacional de Santa Catarina & SC & 2 \\
\hline Universidade do Sul de Santa Catarina & SC & 2 \\
\hline Universidade Federal da Fronteira Sul & SC & 2 \\
\hline Universidade Federal da Paraíba & PB & 2 \\
\hline Universidade Federal de Pernambuco & $\mathrm{PE}$ & 2 \\
\hline Universidade Federal de São João del-Rei & MG & 2 \\
\hline Universidade Federal do Tocantins & TO & 2 \\
\hline Universidade Presbiteriana Mackenzie & $\mathrm{SP}$ & 2 \\
\hline Atuação Empresarial Ltda. & SC & 1 \\
\hline Chiusoli Pesquisas & PR & 1 \\
\hline Conseiller Tecnologia da Informação & PR & 1 \\
\hline Escola Superior de Propaganda e Marketing & SP & 1 \\
\hline Exprinter Liftvans Bolivia & Bolívia & 1 \\
\hline Instituto Brasileiro de Mercado de Capitais (IBMEC) & RJ & 1 \\
\hline Instituto Federal de Educação, Ciência e Tecnologia de Santa Catarina & SC & 1 \\
\hline Instituto Politécnico de Leiria & Portugal & 1 \\
\hline
\end{tabular}




\begin{tabular}{|l|c|c|}
\hline Instituições & Local & $\begin{array}{c}\text { Número de } \\
\text { autores }\end{array}$ \\
\hline Serviço Nacional de Aprendizagem Industrial & SC & 1 \\
\hline Universidade de São Caetano do Sul & SP & 1 \\
\hline Universidade Estadual de Maringá & PR & 1 \\
\hline Universidade Estadual de Mato Grosso do Sul & MS & 1 \\
\hline Universidade Estadual de Montes Claros & MG & 1 \\
\hline Universidade Estadual do Oeste do Paraná & PR & 1 \\
\hline Universidade Federal de Campina Grande & PB & 1 \\
\hline Universidade Federal do Rio de Janeiro & RJ & 1 \\
\hline Universidade Federal do Rio Grande & RS & 1 \\
\hline Universidade Federal Rural do Rio de Janeiro & RJ & 1 \\
\hline Total & & $\mathbf{1 1 3}$ \\
\hline
\end{tabular}

Os dados mostram que a UFSC, a USP, a FGV-SP e a Fundação Universidade Regional de Blumenau foram as instituições que contabilizam o maior número de autores de artigos bibliométricos. Comparando os dados da Tabela 2 com os de Iwamoto, Teixeira e Medeiros (2010), nota-se que a produção dessas três instituições superou a da UNINOvE, detentora da maior produtividade até 20Io. Um dado relevante é que parte expressiva dos trabalhos foi produzida em coautorias concentradas por instituição. Considerando agora a produção por instituições nas regiões políticas brasileiras, pode-se identificar que as instituições com três autores ou mais se concentram nas regiões Sul e Sudeste. No entanto, em relação a essa tendência, a Universidade Federal do Ceará constituiu a exceção, com quatro autores.

Quais as Categorias Utilizadas nos Trabalhos Bibliométricos em Administração no Brasil? Tendo em vista serem Araújo (2002) e Vanti (2002) autores de referência no que se refere a conhecimentos específicos sobre bibliometria, buscamos identificar a presença das categorias por eles mencionadas nos artigos pesquisados, a saber: autores mais citados, autores mais produtivos, origem da literatura e dos autores, procedência institucional, elite da pesquisa, frente de pesquisa, ano, tipo de periódico, 
tipo de evento, fator de impacto, usuários de uma disciplina, padrões de colaboração entre autores, tipo de documento mais utilizado, citação e cocitação, aspectos estatísticos da linguagem, das palavras e das frases e áreas e temas (Tabela 3).

Tabela 3 Categorias de análise utilizadas nos artigos bibliométricos (2003-20I2)

\begin{tabular}{|l|c|}
\hline Categorias & Frequência \\
\hline Ano & 31 \\
\hline Autores mais citados & 26 \\
\hline Temas e pesquisa & 24 \\
\hline Tipo de Periódico & 22 \\
\hline Autores mais produtivos & 20 \\
\hline Origem da literatura e dos autores & 20 \\
\hline Tipo de evento & 16 \\
\hline Instituições dos autores & 10 \\
\hline Elite da pesquisa & 06 \\
\hline Eventos & 06 \\
\hline Frente de pesquisa & 05 \\
\hline Fator de Impacto & 04 \\
\hline Total & 190 \\
\hline
\end{tabular}

Os dados da Tabela 3 mostram que nem todas as categorias sugeridas por Araújo (2002) e Vanti (2002) foram consideradas nos artigos pesquisados, posto que, nos 36 trabalhos analisados, as categorias mais utilizadas foram: ano, autores mais citados e temas e pesquisa, com 31, 26 e 24 artigos, respectivamente. No extremo oposto, as categorias menos utilizadas foram: frente de pesquisa e fator de impacto, com cinco e quatro artigos, respectivamente.

No entanto, a análise dos artigos revelou que foram consideradas outras categorias não contempladas por Araujo (2002) e Vanti (2002). Analisando ainda o corpus por outro ponto de vista, procuramos perceber se os trabalhos apresentaram categorias além das prescritas por esses dois autorese o resultado foi positivo, tal como mostra a Tabela 4, e em quantitativo significativo. 
Tabela 4 Categorias efetivamente utilizadas nos artigos bibliométricos

\begin{tabular}{|l|l|}
\hline Categoria & Frequência \\
\hline Número de referências por artigo & 10 \\
\hline Metodologia adotada & 10 \\
\hline Número de autores por artigo & 9 \\
\hline Tipo de trabalho (teórico, empírico, etc.) & 9 \\
\hline Relações de coautoria & 8 \\
\hline Gênero do autor & 5 \\
\hline Titulação do(s) autor(es) & 5 \\
\hline Relações de cooperação entre instituições & 3 \\
\hline Área de Formação dos autores & 2 \\
\hline Linha de pesquisa dos autores & 2 \\
\hline Tipo de referências citadas pelo artigo (artigo, capítulo, norma, etc.) & 2 \\
\hline Vínculo do autor com a instituição (CLT, Servidor Público, Empre- & 2 \\
\hline sário) & 1 \\
\hline Ano de obtenção da titulação do autor & 1 \\
\hline Forma do trabalho (artigo, resenha, resumo, etc.) & 1 \\
\hline Principais periódicos referenciados em eventos & 1 \\
\hline Relações de cocitação (autores que citam as mesmas referências) & 71 \\
\hline Total & 2 \\
\hline
\end{tabular}

A Tabela 4 mostra a diversidade de categorias, sugerindo que atendem a objetivos diferentes dos pertinentes à bibliometria. Por exemplo, dentre as categorias nota-se que algumas - linha de pesquisa dos autores, titulação, ano de formação, ano de titulação, vínculo do autor com a instituição e gênero - mostram uma preocupação dos autores com o perfil dos pesquisadores e, enquanto metodologia, mostra o foco no conhecimento dos procedimentos metodológicos mais empregados em um determinado campo de conhecimento em Administração.

Refletindo sobre os Resultados

A análise de citações é a técnica mais utilizada em estudos bibliométricos e tem como principal função, segundo Caldas e Tinoco (2004), fornecer ao leitor referências importantes sobre o campo de estudo em questão e mostrar a contribuição de autores que atuam há mais tempo no campo para 
pesquisas atuais. Por meio das citações é possível extrair categorias - autores mais citados, autores mais produtivos, origem da literatura e dos autores, elite da pesquisa, ano, tipo de periódico, tipo de evento e fator de impacto Em nosso estudo, o que ficou evidente, nesse sentido, foi uma concentração geográfica da produção acadêmica citada pelos artigos bibliométricos, no eixo Sul-Sudeste.

Ao analisar os meios mais utilizados para a realização de publicações, percebemos que o evento EnANPAD foi o principal veículo utilizado, respondendo por mais de $70 \%$ dos artigos publicados e, no que se refere aos demais artigos, foram publicados em revistas científicas, como ilustra o Gráfico 2. Ao olhar para os dados, não parece estranho que a EnANPAD seja o principal meio de publicação, e isso mostra que esse encontro é uma porta de entrada para a publicação de artigos inéditos e de pesquisadores em formação na área de Administração de Empresas. Portanto, não se deve negligenciar a baixa frequência de publicação nos demais periódicos. Considerando o EnANPAD como a porta de entrada dos trabalhos científicos produzidos, infere-se que nos anos posteriores ao encontro tais trabalhos são publicados nos periódicos científicos.

Considerando os 36 trabalhos analisados observou-se que os mesmos não apresentam um conjunto de categorias padronizado. Acreditamos que isso prejudica o mapeamento do campo de estudo por não refletir claramente os pontos importantes que poderiam efetivamente contribuir com a produção e evolução do conhecimento científico. É notório o fato de que dentre as 28 categorias contempladas nos artigos estudados, apenas I2 coincidam com aquelas sugeridas por autores proeminentes do campo da bibliometria, dentre eles Vanti (2002). Ademais, embora tais trabalhos sejam denominados de "artigos bibliométricos", isso não significa que se caracterizam como tais.

Uma outra possível suposição é a de que as categorias sugeridas pela bibliometria não atendam à finalidade e à razão de porque os estudos bibliométricos em Administração tem sido realizados.

O que sugere o conjunto de categorias empregadas nos estudos pesquisados e que não são comumente citadas na literatura de bibliometria? Um das 
possibilidades é que os estudos bibliométricos em Administração estejam atendendo a uma finalidade que é a de analisar a qualidade da produção dentro de uma determinada subárea de conhecimento, identificando fronteiras e zonas de conforto, categoria esta sugerida por Moretti e Campanario (2008). Isto é, talvez nós, pesquisadores da Administração, na tentativa de querermos contribuir para o avanço do conhecimento em nossa área do conhecimento estejamos em busca de um mapa-guia de como fazer o levantamento da literatura, de forma a sistematizar uma busca de informação para possibilitar alternativas de escolha de por onde começar uma análise que nos possibilite identificar frestas e por entre elas caminhar, gerando, assim, avanços.

Nesse sentido, Mattos (2004), com seus questionamentos, já nos apontou alguns cuidados e caminhos ao se referir aos critérios para a escolha das categorias, destacando, por exemplo, a ambiguidade do significado de categorias como "citações", questionando o que significam as "não-citações", "idade" da obra citada, chamando-nos a atenção particularmente para o que não é comum, para os resultados que não são estatisticamente modais.

A análise dos artigos bibliométricos feita neste trabalho, nos permite refletir sobre o papel reforçador que tais estudos desempenham ao apontar os autores mais citados, a metodologia mais empregada, os temas mais pesquisados, em sua maior parte sem uma discussão aprofundada dos resultados. Para pesquisadores jovens eles podem servir como um sinalizador do caminho a seguir no sentido de "vamos por onde todos e, particularmente os mais citados, estão caminhando". O que não quer dizer que não se deva seguir esse caminho, porém é preciso fazê-lo de forma consciente e não oportunista.

Que caminho então seguir para conhecermos e nos posicionarmos em um campo de estudo em um tema? Abandonar os estudos "bibliométricos"? Não necessariamente. Eles têm a sua utilidade, particularmente se, mediante os resultados encontrados, nos posicionarmos com olhos críticos e não com de meros engrossadores da mesmice. Uma das categorias que não encontramos presente nos artigos analisados foi a da análise paradigmática, ou seja: qual tem(êm) sido a(s) abordagem(ns) paradigmáticas que tem(êm) 
subsidiado um determinado tema que pretendemos conhecer melhor? Com que saliência essas abordagens têm ocorrido ao longo dos anos? Outra questão que nos parece interessante é a origem dos estudos realizados, quer dizer: de quais instituições e países? Como a cultura do país, o curriculum oculto dessas instituições, pode ter vindo ao longo do tempo influenciando a geração do conhecimento? Como isso pode se refletir ao realizarmos os nossos estudos em uma outra realidade cultural e institucional?

Em suma: a quem estamos dando voz em nossos estudos? O que terão a dizer sobre os mesmos temas autores latinoamericanos, brasileiros pensantes dos mais distantes rincões deste país? Qual a efetiva contribuição que estamos oferecendo com os nossos estudos bibliométricos? Essa é uma questão para refletirmos, e antes de nos preocuparmos em seguir um determinado conjunto de categorias bibliométricas é bom que nos perguntemos o que pretendemos com elas e com que olhar sobre elas conduzimos nosso processo de análise e, então, deixar isso claro. 


\section{CONSIDERAÇÕES FINAIS}

Este artigo teve como objetivo analisar e discutir a produção de estudos bibliométricos em Administração no Brasil, propondo uma reflexão sobre o emprego da bibliometria, de maneira a sugerir alternativas para o uso das técnicas segundo formas que atendam à finalidade de subsidiar a pesquisa sobre um determinado tema. Objetivamos, ainda, nos debruçar sobre o status quo e vislumbrar, a partir daí, possíveis avanços a serem feitos sobre um campo específico de estudo em Administração.

Os resultados mostraram que os artigos contemplam categorias que nem sempre são observadas pela bibliometria, o que revela que esse tipo de técnicas não atende completamente às necessidades dos pesquisadores que as empregam. No entanto, não se trata de abandonar o emprego da abordagem da bibliometria, mas de refazer o seu uso, isto é, não se trata apenas de identificar o que é mais produzido e por quem, mas usá-la de modo que nos permita identificar frestas que facultem perceber o que não está sendo produzido, abordagens não contempladas, buscar vozes não ouvidas e contrapô-las ao status quo. Com essa perspectiva talvez seja possível gerar conhecimento novo, sob enfoques novos, permitindo-nos um olhar que foge ao do colonizador.

Propomos, assim, a seguinte classificação para os estudos bibliométricos em Administração: a) estudos que se concentrem nas categorias bibliométricas que contemplem leis como as de Lotka, Zipf e Price, visando macroanálises, como sugere Macias-Chapula (1998), quando o objetivo for discutir políticas públicas de geração do conhecimento e, some-se àquelas, a análise da produção do conhecimento por instituição, assim como pela origem geográfica dos autores; b) categorias relacionadas ao perfil dos autores, quando o objetivo foi analisar a maturidade acadêmica e as características demográficas dos pesquisadores do campo em estudo; c) distribuição do conhecimento no tempo e no espaço, identificando a evolução da produção no tempo e a distribuição geográfica; d) identificar os autores mais influentes e as influências que recebem, mediante o levantamento dos autores mais produtivos e cocitações; e) e, ainda, identificar abordagens epistêmica e 
metodológicas dominantes e não-dominantes no campo.

Sugerimos que os estudos bibliométricos finalizem a sua análise mostrando não apenas os aspectos dominantes, mas que analisem criticamente os menos presentes ou ausentes, apontando para agendas de pesquisa inovadoras, para alternativas e realidades aparentemente invisíveis. O emprego de categorias de análise não contempladas na bibliometria que visem a atender às necessidades de pesquisa no campo da Administração, assim como o requisito de que suas análises não se esgotem nos aspectos dominantes, como se dá quando fica apenas na figura de um quadro, mas ir além e contemplar o que aparentemente não esteja visível, implica na transposição da finalidade dos estudos bilbiométricos em Administração, sendo mais apropriado denominá-los de "Quasi bibliométricos". Este artigo, em sua essência, visou contribuir para a reflexão sobre o fazer bibliométrico quando aplicado com o objetivo de buscar avanço genuíno de conhecimento. 


\section{REFERÊNCIAS}

ALVARENGA, L. Bibliometria e arqueologia do saber de Michel Foucault: traços de identidade teórico-metodológica. Ciência da Informação. Brasília, v. 27, n.3, p. 1-9, 1998.

ANDRADE, M. A. M.; JOAQUIM, N. F.; GOSLING, M. Metodologias de análise de imagem no marketing: um estudo bibliométrico dos anais do ENANPAD. Encontro de Marketing da ANPAD, 5, 2012, Rio de Janeiro. Anais... Rio de Janeiro: ANPAD, 2012.

ARAÚJO, C. A. Bibliometria: evolução histórica e questões atuais. Em Questão, v. 12, n. 1, p. 11-32, 2002.

BARDIN, L. Análise de Conteúdo. Lisboa: Edições 70, 1979.

BERTERO, C. O.; CALDAS, M. P.; WOOD Jr., T. Produção Científica em Administração de Empresas: Provocações, Insinuações e Contribuições para um Debate Local. RAC, v. 3, n. 1, p. 147-78, 1999.

(Orgs.). Produção científica em Administração no Brasil: o estado da arte. São Paulo: Atlas, 2005.

BOTELHO, L. L. R.; MACEDO, M.; GAUTHIER, F.O.; DUARTE, M.A.T. Revisão bibliométrica sobre mudança organizacional e aprendizagem gerencial em uma organização intensiva em conhecimento. In: ENANPAD, 35., 2011, Rio de Janeiro. Anais... Rio de Janeiro: ANPAD, 2011.

BRADFORD, S. C. Sources of information on specific subjects. Engineering, v. 137, n.1, p. 85-6, 1934.

BRAGA, G. Relações bibliométricas entre a frente de pesquisa (research front) e revisões da literatura: estudo aplicado à Ciência da Informação. Ciência da Informação, v. 2, n. 1, p. 9-26, 1973.

CALDAS, M. P.; TINOCO, T.; CHU, R. A. Análise bibliométrica dos artigos de RH publicados no ENANPAD na década de 1990: um mapeamento a partir das citações dos heróis, endogenias e jactâncias que fizeram a história da produção científica da área. In: EnANPAD, 27., 2003, Atibaia/SP. Anais... Atibaia/SP: ANPAD, 2003.

Pesquisa em gestão de recursos humanos nos anos 1990: um estudo

bibliométrico. RAE eletrônica, v. 44, n. 3, p. 100-114, 2004.

CALVOSA, M. V. D. Uma pesquisa bibliométrica sobre valores pessoais: a análise global de instrumentos de mensuração de valores pessoais. In: Simpósio de Gestão de Inovação Tecnológica, 27., 2012, Salvador/BA. Anais... Salvador/BA, 2012.

CAMARGOS, M. A.; SILVA, W. A. C.; DIAS, A. T. Análise da produção científica em Finanças entre 2000-2008: um estudo bibliométrico dos encontros da ANPAD. In: EnANPAD, 33., 2009, São Paulo. Anais... São Paulo: ANPAD, 2009.

CANTALICE, F. L. B. M.; FILHO, J. C. L. da S.; JÚNIOR, C.D.S.C.B.; FREITAS, A.R.P. Fair Trade (Comércio Justo) como um “Tópico Quente” internacional: análise 
bibliométrica e reflexão sobre possíveis abordagens do tema. In: EnNANPAD, 34., 2010, Rio de Janeiro. Anais... Rio de Janeiro: ANPAD, 2010.

CHAN, B. L.; MILANI FILHO, M. A. F.; MARTINS, G. A. Utilização da análise de correspondência para uma abordagem bibliométrica: relação entre a área temática $\mathrm{e}$ a plataforma teórica. In: EnANPAD, 31., 2007, Rio de Janeiro. Anais... Rio de Janeiro: ANPAD, 2007.

CINTRA, R. F.; MUNCK, L.; VIEIRA, S. F. A. A produção intelectual em teoria institucional: uma análise nos principais periódicos brasileiros a partir do método bibliométrico. In: ENEO, 5., 2012, Curitiba. Anais... Curitiba: ANPAD, 2012.

DELFINO, I. A. L.; SILVA, A. B.; ROHDE, L. R. A produção acadêmica sobre liderança no brasil: uma análise bibliométrica dos artigos publicados em eventos e periódicos entre 1995 e 2009. In: EnANPAD, 34., 2010, Rio de Janeiro. Anais... Rio de Janeiro: ANPAD, 2010.

FAVORETO, R. L.; VIEIRA, S. F. A.; SHIMADA, A. T. A produção intelectual em RBV: uma incursão bibliométrica nos principais periódicos nacionais. In: EnANPAD, 36. , 2012, Rio de Janeiro. Anais... Rio de Janeiro: ANPAD, 2012.

FONSECA, E. N. Bibliografia estatística e bibliometria: uma reivindicação de prioridades. Ciência da Informação, v. 2, n. 1, p. 5-7, 1973.

FRANCISCO, E. R. RAE-eletrônica: exploração do acervo à luz da bibliometria, geoanálise e redes sociais. RAE. v. 51, n. 3, p. 280-306, 2011.

GARFIELD, E. The agony and the ecstasy: the history and meaning of the Journal Impact Factor. In: International Congress on Peer Review And Biomedical Publication, 5., 2005, Chicago. Proceedings... Chicago: JAMA and Archives Journals and BMJ Publishing Group, 2005.

GUEDES, V.L.S.; BORSCHIVER, S. Bibliometria: uma ferramenta estatística para a gestão da informação e do conhecimento, em sistemas de informação, de comunicação e de avaliação científica e tecnológica. In: Cinform, 6., 2005, Salvador/BA. Anais... Salvador/BA: UFBA, Instituto de Ciência da Informação, 2005.

JUDICE, V. M. M.; PEREIRA, J. F. Publicações científicas brasileiras sobre comércio eletrônico na área de administração (1997- 2007): um estudo bibliométrico. In: Simpósio de Gestão da Inovação Tecnológica, 25., 2008, Brasília/DF. Anais... Brasília/DF: 2008.

LACERDA, R. T. O.; ENSSLIN, L.; ENSSLIN, S. R. Uma análise bibliométrica da literatura sobre estratégia e avaliação de desempenho. Gest. Prod, v. 19, n. 1, p. 59-78, 2012 .

LOTKA, A. J. The frequency distribution of scientific productivity. Journal of the Washington Academy of Sciences, v. 16, n. 12, p. 317-23, 1926.

MACEDO, M. A. S.; CASA NOVA, S. P. C.; ALMEIDA, K. Mapeamento e análise bibliométrica da utilização da análise envoltória de dados (DEA) em estudos das áreas de Contabilidade e Administração. In: EnANPAD, 31., 2007, Rio de Janeiro. Anais... Rio de Janeiro: ANPAD, 2007. 
MACHADO-DA-SILVA, C. L.; FILHO, E.R.G.; ROSSONI, L.; GRAEFF, J.F. Periódicos brasileiros de Administração: análise bibliométrica de impacto no triênio 2005-2007. RAC-Eletrônica, v. 2, n. 3, p. 351-373, 2008.

MACIAS-CHAPULA, C. A. O papel da informetria e da cienciometria e sua perspectiva nacional e internacional. Ciência da Informação, v. 27, p. 134-140, 1998.

MALDONADO, M. U.; SANTOS, J. L. S.; SANTOS, R. N. M. Inovação e conhecimento organizacional: um mapeamento bibliométrico das publicações científicas até 2009. In: ENANPAD, 34., 2010, Rio de Janeiro. Anais... Rio de Janeiro: ANPAD, 2010.

MARQUES, T. O.; PETRI, S. M.; SCHULTZ, C. A. Valor justo aplicado nos instrumentos financeiros: um estudo bibliométrico das pesquisas nacionais e internacionais. In: EnANPAD, 36., 2012, Rio de Janeiro. Anais... Rio de Janeiro: ANPAD, 2012.

MARTINS, R. A.; SERRA, F.A.R.; FERREIRA, M.P.; REIS, N.R. Análise da produção científica sobre empresas familiares: um estudo bibliométrico. In: EnANPAD, 36., 2012, Rio de Janeiro. Anais... Rio de Janeiro: ANPAD, 2007.

MATTOS, P. L. C. L. "Bibliometria”: a metodologia acadêmica convencional em questão. RAE eletrônica, v. 3, n. 2, p. 280-306, 2004.

MORETTI, S. L. A.; CAMPANARIO, M. A. A Produção Intelectual Brasileira em Responsabilidade Social Empresarial - RSE sob a Ótica da Bibliometria. RAC, v. 13, Edição Especial, p. 68-86, 2009.

MORETTI, S. L. A.; CAMPANARIO, M. A. Para sair da zona de conforto: análise bibliométrica dos artigos sobre responsabilidade social empresarial - RSE na ENANPAD. In: EnANPAD, 32., 2008, Rio de Janeiro. Anais... Rio de Janeiro: ANPAD, 2008.

; FIGUEIREDO, J. C. Análise bibliométrica da produção sobre responsabilidade social das empresas no ENANPAD: evidências de um discurso monológico. In: EnANPAD, 31., 2007, Rio de Janeiro. Anais... Rio de Janeiro: ANPAD, 2007.

NOGAMI, V. K. C.; PACAGNAN, M. N. Consumo da base da pirâmide: uma análise bibliométrica do estado da arte na produção acadêmica no Brasil. In: EnANPAD, 35., 2011, Rio de Janeiro. Anais... Rio de Janeiro: ANPAD, 2011.

PEREIRA, V. R.; CARVALHO, M. M.; ROTONDARO, R. G. Um estudo bibliométrico sobre a evolução da pesquisa da qualidade em serviço. Produção. v. 22, n. ahead of print, p. 1-17, 2012.

PEREIRA, G. M. C.; YEN-TSANGB, C.; MANZINIC, R.B.; ALMEIDAD, N.V. Sustentabilidade socioambiental: um estudo bibliométrico da evolução do conceito na área de gestão de operações. Produção, v. 21, n. 4, p. 610-619, 2011. 
PODSAKOFF, P. M.; MACKENZIE, S.B.; PODSAKOFF, N.P.; BACHRACH, D.G. Scholarly influence in the field of management: a bibliometric analysis of the determinants of university and author impact in the management literature in the past quarter century. Journal of Management, v. 34, n. 4, p. 641-720, 2008.

PRICE, J. D. S. Little science, big science. New York: Columbia University Press, 1963.

PRITCHARD, A. Statistical bibliography or bibliometrics. Journal of Documentation, v. 25, n. 4, p. 348-349, 1969.

RASERA, M.; CHEROBIM, A. P. M. S. Investimentos em Tecnologia da Informação e Inovação: Estudo Bibliográfico e Bibliométrico da Produção Científica no EnADI 20072009. In: Simpósio de Gestão da Inovação Tecnológica, 26., 2010, Vitória/ES. Anais... Vitória/ES, 2010.

ROSSI, C. A. V.; BORTOLI, L. V.; CASTILHOS, R. B. Análise bibliométrica da contribuição de marketing para outras ciências. In: Encontro de Marketing da ANPAD, 5., 2012, Curitiba. Anais... Curitiba: ANPAD, 2012.

SANTOS, L.; WALTER, S.A.; BACH, T.M.; FERNANDES, L.N.; SCHROEDER, U. Redes sociais e bibliometria: uma análise longitudinal da temática de logística do período de 1997 a 2011. In: EnANPAD, 36., 2012, Rio de Janeiro. Anais... Rio de Janeiro: ANPAD, 2012.

SCHMITT, M. T. B; CLEMENTI, J.; SOUZA, J.A.; DANDOLINI, G.A.; TEZA, P.; DOROW, P.F. Inteligência competitiva na web: uma análise bibliométrica do estado da literatura. In: EnANPAD, 36., 2012, Rio de Janeiro. Anais... Rio de Janeiro: ANPAD, 2012.

SEHNEM, S.; OLIVEIRA, M.A.S.; FERREIRA, E.; ROSSETTO, A.M. Gestão e estratégia ambiental: um estudo bibliométrico sobre o interesse do tema nos periódicos acadêmicos brasileiros. REAd, v. 72, n. 2, p. 468-93, 2012.

SOLA, G. L.; BONACIM, C. A. G. Avaliação Bibliométrica de Periódicos Brasileiros: Contrastando a Metodologia Qualis-CAPES com o Modelo de Krzyzanowski e Ferreira (1998). In: EnANPAD, 35., 2011, Rio de Janeiro. Anais... Rio de Janeiro: ANPAD, 2011.

SOUZA, M. T. S.; RIBEIRO, H.C.M.; JÚNIOR, C.M.; CORRÊA, R. Perfil e Evolução da pesquisa em sustentabilidade ambiental: uma análise bibliométrica. In: EnANPAD, 35. , 2011, Rio de Janeiro. Anais... Rio de Janeiro: ANPAD, 2011.

SPLITTER, K.; ROSA, C. A.; BORBA, J. A. Uma análise das características dos trabalhos "ditos" bibliométricos publicados no enanpad entre 2000 e 2011. In: EnANPAD, 36., 2012, Rio de Janeiro. Anais... Rio de Janeiro: ANPAD, 2012.

TONELLI, M. ; CALDAS, M.; LACOMBE, B e TINOCO, T. Produção acadêmica em Recursos Humanos no Brasil: 1991-2000. RAE, v. 43, n. 1, p. 105-122, 2003.

VANTI, N. A. P. Da bibliometria à webometria: uma exploração conceitual dos mecanismos utilizados para medir o registro da informação e a difusão do conhecimento. Ciência da Informação, v. 31, n.2, p. 152-62, 2002. 
VIEIRA, F.G.D. Narciso sem espelho: a publicação brasileira de marketing. RAE, v. 43, n. 1, p. 81-90, 2003.

WALTER, S. A.; BACH, T. M.; BARBOSA, F. Estrutura das Redes Sociais e Bibliometria: Uma análise longitudinal da Abordagem de Estratégia como Prática. In: EnANPAD, 36., 2012, Rio de Janeiro. Anais... Rio de Janeiro: ANPAD, 2012.

; SILVA, E. D. Visão baseada em recursos: um estudo bibliométrico e de redes sociais da produção científica da área de estratégia do ENANPAD 1997-2007. In: EnANPAD, 32., 2008, Rio de Janeiro. Anais... Rio de Janeiro: ANPAD, 2008.

WASSERMAN, S.; FAUST, K. Social network analysis: methods and applications. Cambridge University Press, 1994.

WORMELL, I. Informetria: explorando bases de dados como instrumentos de análise. Ciência da Informação, v. 27, n. 2, p. 210-16, 1998.

ZANINI, G. B.; PINTO, M. D. S.; FILIPPIM, E. S. Bibliometria a serviço do conhecimento: análise de citação do tema de interesse gestão do conhecimento do ENANPAD (2007 a 2010). In: EnANPAD, 36., 2012, Rio de Janeiro. Anais... Rio de Janeiro: ANPAD, 2012.

ZIPF, G. K. Human behavior and the principle of least effort. Cambridge, MA: Addison Wesley, 1949. 


\section{DADOS DOS AUTORES}

\section{MARIA LUISA MENDES TEIXEIRA^ malluluisa@gmail.com}

Doutora em Administração de Empresas pela FEA/USP

Instituição de vinculação: Universidade Presbiteriana Mackenzie

São Paulo/SP - Brasil

Áreas de interesse em pesquisa: Comportamento Organizacional.

^Rua Consolação, 896 Consolação São Paulo/SP 01307-000

\section{HELGA MIDORI IWAMOTO helga.iwamoto@gmail.com}

Doutora em Administração pela Universidade Presbiteriana Mackenzie

Instituição de vinculação: Universidade Federal do Tocantins

Palmas/TO - Brasil

Áreas de interesse em pesquisa: Psicologia Intercultural, Gênero e Gestão Social.

\section{ANA LÚCIA MEDEIROS analucia@uft.edu.br}

Mestre em Economia pela UFPB

Instituição de vinculação: Universidade Federal do Tocantins

Palmas/TO - Brasil

Áreas de interesse em pesquisa: Teorias Organizacionais, Gestão de Pessoas e

dignidade do trabalhador. 